\title{
Mother's Role and Knowledge in Young Children Feeding Practices on the Nutritional Status of Infant and Toddler
}

\author{
Yusrawati Hasibuan $^{1}$, Ardiana Batubara ${ }^{1} \&$ Suryani $^{1}$ \\ ${ }^{1}$ Department of Midwifery, Medan Health Polytechnic, Ministry of Health, Medan Province, Indonesia \\ Correspondence: Rumelia L. Sembiring, Department of Midwifery, Medan Health Polytechnic, Ministry of Health, \\ 20141, Indonesia. Tel: 62-813-9604-5555. E-mail: rumelia.lubina@yahoo.co.id
}

Received: April 11, 2019 Accepted: April 29, 2019 Online Published: May 14, 2019

doi:10.5539/gjhs.v11n6p158 URL: https://doi.org/10.5539/gjhs.v11n6p158

\begin{abstract}
Adequate nutrition, beginning in early stages of life, is crucial to ensure good physical and mental development as well as long-term health. Efforts in improving nutritional status in Indonesia are mostly focused to the vulnerable groups, mainly infant (baby under one year old) and toodler (baby under two years old). Childhood underweight and overweight are an important public health problem, as these conditions tend to have a chronic condition that cause a wide range of future morbidity. Overweight in young children is associated with future cardiovascular diseases, diabetes, and psychosocial problems and stunted children suffer from impaired growth with permanent consequences in their adult life that face a high risk of morbidity and mortality. In this case, parents (especially mothers as the role models) are mostly responsible on healthy eating behaviors of their young children. With refers to this empirical fact, the objective of this study was to assess the association of mother's role and knowledge in feeding young children practices on the nutritional status of their infants and toddlers. Analytical cross-sectional study was used in this study. The sampling technique was purposive sampling and a total of samples were 136 mothers. Data were processed and analyzed by using a computer program with a chi-square test at a significance level of $95 \%$. Overall, results of the statistical test showed that there were no significant associations between role and knowledge of the mothers and adequate nutritional status of their infants and toddlers at a $p$-value of $0.544>$ 0.05 and $p$-value of $0.749>0.05$ respectively. Based on results of this study, more intensive nutrition intervention programs are necessary to prevent poor nutritional status of young children particularly for infant and toddler, conducting more active coordination in health cross-programs, and improving nutrition counseling programs and suitable health services for the concerned public.
\end{abstract}

Keywords: maternal roles, nutritional status

\section{Introduction}

Adequate nutrition, beginning in early stages of life, is crucial to ensure good physical and mental development and long-term health (WHO, 2014). More serious efforts are necessary to achieve adequate nutrition in improving early stages of life of individual, mainly infant (baby under one year old) and toodler (baby under two years old). Childhood underweight and overweight are an important public health problem, as these conditions tend to have a chronic condition that include underweight (Greco et al., 1995) and overweight (Reilly et al., 2003; Freedman et al., 2009) that cause a wide range of future morbidity. Overweight in children is associated with future cardiovascular diseases (Freedman et al., 2009; Eriksson et al., 2001), diabetes (Eriksson et al., 2001), and psychosocial problems (Reilly et al., 2003; Griffiths et al., 2006). Moreover low height-for-age or stunting is a key indicator of chronic undernutrition. Stunted children suffer from impaired growth with permanent consequences in their adult life, and face a high risk of morbidity and mortality (Black et al., 2008; Dewey et al., 2011; Grantham-McGregor et al., 2007; McDonald et al., 2013; Victora et al., 2008). In this case, parents are mostly responsible on healty eating behaviors of their children, particularly mothers as the role models of their children about eating behaviors (Yabanci et al., 2013; Yardımc1 et al., 2016)

There are several factors influencing children's eating behaviors that include family environment, maternal influences, paternal influences, family meals, education and socioeconomic status, child eating behavior, food preferences, early feeding practice, obesogenic environment and media influences (Scaglioni et al., 2018).

Specifically, parent's feeding practices are significantly associated with the feeding behavior of toddlers and preschool-age children (Sanders et al., 1993). Feeding difficulties are one of the most common behavioral 
disturbances in young children range from transient, relatively minor behavioral problems at dinner time (e.g., messy, noisy, or disruptive mealtime behavior) to total food refusal, resulting in life-threatening malnutrition (Luiselli, 1989), resisting parental attempts to feed them, excessive slowness, highly selective eating, gagging, regurgitation, and disruptive mealtime behaviors (e.g., tantrums). These behaviors can result in serious medical consequences, including malnutrition (Sanders et al., 1993).

Psychological and behavioral factors implicated in feeding disorders include parental characteristics (maternal depression, household disorganization, and social isolation), parents' beliefs about nutrition (Pugliese et al., 1987), and parent-child interaction during mealtimes (Agras et al., 1988). In view of the national level, Act of the National Health No. 36 of 2009 states that the main priority of the improvement of nutritional status are the vurnerable groups mainly infant and toddler (Ministry of Health of the Republic of Indonesia).

Indonesia is one among 117 countries is now facing three national nutritional problems for children under five years old that incude stunting, wasting and overweight (Global Nutrition Report, 2014 Nutrition Country Profile Indonesia). The prevalence rates of the three nutritional problems for children under five years old in this country are stunting (37.2\%), wasting (12.1\%) and overweight (11.9\%) respectively (IFPRI, 2014). Minister of Health of the Republic of Indonesia stated that the last rate of nutritional status in 2016 has improved. This is confirmed from the progress of exclusive breastfeeding fulfillment and reduction of stunting (Department of Health of the Republic of Indonesia, 2016). Despite nutritional status in Indonesia has been improved from the reduction of stunting of young children from $37.2 \%$ to $29 \%$, Indonesia is still in the category of the WHO's undernutritional status.

On the basis of the Indonesian National Health Survey in 2017, the prevalence rate of malnutrition for children under five years old in terms of weight-for-age (WFA) indicator is 3.8\% and of undernutritional status for children under five years old is $14.0 \%$. The prevalence rates of severe stunting and of moderate stunting for children under five years old in terms of length/height-for-age (LHFA) indicator are $9.8 \%$ and $19.8 \%$ and the prevalence rates of severe wasting and moderate wasting for children under five years old in terms of weight-for-length (WFL) indicator are $2.8 \%$ and $6.7 \%$ respectively. With refers to the classification of age, the prevalence rates of undernutrional status, moderate stunting and moderate wasting for children less than five years old in 2017 are $17.8 \%, 29.6 \%$ and $9.5 \%$ respectively (Ministry of Health of the Republic of Indonesia, 2017).

Viewed from the provincial level, nutritional status of children aged 0-59 months in North Sumatera province in terms of weight-for-age (WFA) indicator in the category of poor nutrition and undernutrional status are $5.3 \%$ and $13.1 \%$, of length/height-for-age in the category of severe stunting and stunting are $12,5 \%$ and $16 \%$, and of weight-for-length (WFL) in the category of severe wasting and wasting are $5.7 \%$ and $7.7 \%$ respectively. With refers to nutritional status of children under five years old from the national survey in 2017, nutritonal status of children under five years old in Deli Serdang regency of North Sumatera province in the underweight, of stunting, of wasting dan of obese are $12.6 \%, 33.3 \%, 5.0 \%$ dan $10.6 \%$ respectively. On the whole, nutritional problems in this regency are classified in the category of acute-chronic (Ministry of Health of the Republic of Indonesia, 2017).

From the preliminary survey in the health service area of the Namorambe Community Health Center that serves 36 villages and 47 integrated counseling health posts, a total of registered young chilren under five years old at this community health center in 2017 are 4915 children, of which 13 young children aged 6-25 months (11 males and 2 females) are in the category of undernutritional status. With refers to results of reviews of some literatures and the preliminary field survey, the authors of this study intend to assess mother's role and knowledge in infant and toddler feeding practices on their nutritional status in the health service area of the Namarombe Community Health Center in Deli Serdang regency in 2018.

\section{Methods of the Study}

\subsection{Sample Populations and Design of the Study}

This study was descriptive cross-sectional study. A total number of mothers registered in the health service area of the Namorambe Community Health Center in Deli Serdang regency in 2018 are 4915 mothers. Sample size was determined using several parameters were used for sample size calculation, and the highest estimated sample size was chosen to maximize the required sample size. A simple mean formula, $N=(1.96 \times \sigma / \Delta)^{2}$ was used to calculate the selected sample size, with standard deviation $(\sigma)$ of 3.4 and effect size $(\Delta)$ of 0.75 referred from Mitra et al. (2012) and Lim et al. (2018). A 50\% dropout rate (calculated/1 - dropout rate) and hence a total of samples were 136 mothers. Field observers were health practitioner assistants domiciled in the same subdistrict not far from the residences of the study subjects (respondents). 


\subsection{Assessment of Mother'S Role and Knowledge}

Eating behavioral questionnaire referred to a standard questionnaire (Wardle et al., 2001) to determine the children eating behaviors and nutritional knowledge levels of the mothers referred also to standard questionnaires (Food and Agriculture Organization of the United Nations, 2014; UNICEF, 2014) with some adjustments according to the Indonesian context.

The anthropometric indicators in the form of indices to identify nutritional status of infant and toddler were weight-for-age, weight-for-length/height and length/height-for-age (WHO 2008; WHO 2016; U.S. Centers for Disease Control and Prevention 2016). Indicators of nutritional status of children aged 6-36 months were measured based on the antropometric indices of children aged 6-36 months. The instruments used for measuring anthropometric indicators were a measuring board, a measuring tape and a weight scale. Mother's role and knowledge in infant and toddler feeding practices on the nutritional status of their young children eating behaviors were observed and scored from data of the questionnaire when they gave feeding responses to their infants and toddlers in the questionnaire and face-to-face interview.

Determination of nutritional status of children under five years old at the Namorambe Community Health Center in Deli Serdang regency referred to the standard measurement of the anthropometric indicators as stated in the Decree of Health Minister No.1995/Minister of Health/Decree/XII/2010, Ministry of Health of the Republic of Indonesia. With refers to this standard, each child (6-36 months) was classified in the category of non-normal nutritional status when one of the anthropometric indicators was not fulfilled by each child.

\subsection{Ethical Considerations}

This study received ethical clearance from the Research and Ethics Committee of Medan Health Polytechnic, Ministry of Health, Medan Province and was registered in 0306/KEKO/POLTEKKES KEMENKES MEDAN/2018.

\subsection{Data Management and Analysis}

Data were analyzed using the Statistical Package for Social Science (SPSS) version 20 for Windows. For the statistical analyses of the data table showing percentage (\%) values were prepared and used chi-square test. Alpha levels of $<0.05$ were used as the criteria to determine statistical significance.

\section{Results}

\subsection{Data of the Study Subjects (Mothers and Children 6-36 Months) Were Classified Into Several Categories}

Table 1. Category of age and of gender of the children aged 6-36 months

\begin{tabular}{lll}
\hline Variables & $\mathbf{n}(\mathbf{1 3 6})$ & \% \\
\hline Age & 51 & 37.5 \\
6-12 months & 60 & 44.1 \\
12-24 months & 25 & 18.4 \\
24-36 months & & \\
\hline Gender & 67 & 49.3 \\
Male & 69 & 50.7 \\
Female &
\end{tabular}

As shown in Table 1, the most frequently observed children are identified in the age category of 12-24 months accounted for 60 children (44.1\%). 
Table 2. Category of education and of occupation of the mothers, and frequencies of each mother in nurturing care his children including one child aged 6-38 months

\begin{tabular}{lll}
\hline Variables & $\mathbf{n}(\mathbf{1 3 6})$ & $\mathbf{\%}$ \\
\hline Education & 10 & 7.4 \\
University & 91 & 66.9 \\
Senior high school & 26 & 19.1 \\
Junior high school & 9 & 6.6 \\
Elementary school & & \\
\hline Occupation & 6 & 4.4 \\
Government employee & 24 & 17.6 \\
Private employee & 106 & 77.9 \\
Housewife & & \\
\hline Number of children & 39 & 28.7 \\
One & 55 & 40.4 \\
Two & 31 & 22.8 \\
Three & 9 & 6.6 \\
Four & 2 & 1.5 \\
Five & & \\
\hline
\end{tabular}

In Table 2, the most frequently observed mothers are identified in the category of senior high school accounted for 91 mothers $(66.9 \%)$ and the least frequently observed mothers are identified in the category of elementary school accounted for 9 mothers $(6.6 \%)$. In view of the occupation, most mothers are housewives accounted for 106 mothers $(77.9 \%)$ and frequencies of the mothers in the category of government employee and of private employee are 30 mothers $(22 \%)$. In view of frequencies of the mothers who give nurturing care the number of children (including one child aged 6-36 months), of the mothers in the category of nurturing care 2 children (including one child aged 6-36 months) are 55 mothers (40.4\%), of the mothers in the category of nurturing care 4 children (including one child aged 6-36 months) are 9 mothers (6.6\%), and of the mothers in the category of nurturing care 5 children (including one child aged 6-36 months) are 2 mothers (1.5\%) respectively.

Table 3. Frequencies of the children aged 6-36 months according to their anthropometric indicators and nutritional status from the analysis of samples of children aged 6-36 months

\begin{tabular}{lll}
\hline Anthropometric Indicators \& Nutritional Status & $\mathbf{n}(\mathbf{1 3 6})$ & $\mathbf{\%}$ \\
\hline Weight-for-age & 124 & 91.2 \\
Normal/ideal & 4 & 2.9 \\
Overweight & 8 & 5.9 \\
Underweight & 121 & \\
\hline Weight-for-length & 6 & 89.0 \\
Normal/ideal & 9 & 4.4 \\
Obese & & 6.6 \\
Wasting & 129 & \\
\hline Length/height-for-age & 2 & 94.9 \\
Normal/ideal & 5 & 1.5 \\
Taller & & 3.7 \\
Stunting & 118 & 86.8 \\
\hline Nutritional status & 18 & 13.2 \\
Normal/ideal & & \\
Non-normal & & \\
\hline
\end{tabular}


As shown in Table 3, frequencies of the children aged 6-36 months that refer to the weight-for-age (WFA) indicator in the category of normal weight/ideal, of overweight, and of underweight are 124 children $(91.2 \%), 4$ children (2.9\%) and 8 children (5.9\%) respectively. Frequencies of the children aged 6-36 months that refer to the weight-for-length (WRL) indicator in the category of normal weight/ideal, of obese and of wasting are 121 children $(89.0 \%), 6$ children $(4.4 \%)$ and 9 children (4.4\%) respectively. Frequencies of the children aged 6-36 months that refer to the length/height-for-age (L/HFA) indicator in the category of normal, of taller and of stunting are 129 children (94.9\%), 2 children (1.5\%) and 5 children (3.7\%) respectively. Of 136 children aged 6-36 months as shown in Table 3, frequencies of the children aged 6-36 months in the category of normal status are 118 children $(86.8 \%)$ and of non-normal nutritional status are 18 children (13.2\%) respectively.

Table 4. Frequencies of the mothers according to their role and knowledge on the nutritional status of their infants and toddlers derived from the statistical analysis of data

\begin{tabular}{lll}
\hline & $\mathrm{n}(136)$ & $\%$ \\
\hline Role & 88 & 64.7 \\
Good & 48 & 35.3 \\
Poor & & \\
\hline Knowledge & 69 & 50.7 \\
Good & 67 & 49.3 \\
Poor & & \\
\hline
\end{tabular}

In Table 4, frequencies of the mothers according to their role on the nutritional status of their children in the category of poor level were 48 mothers (35.3\%), and frequencies of the mothers according to their knowledge in food feeding practices on the nutritional status of their children in the category of good level and of poor level and poor are not quite difference in the score of $7 \%$ and the ereuqencies of the mothers in the category of good knowledge were 69 mothers $(50.7 \%)$.

Table 5. Association of role and knowledge of the mothers and nutrional status of their children aged 6-36 months from the analysis of data

\begin{tabular}{|c|c|c|c|c|c|c|c|c|}
\hline \multirow{3}{*}{ Variable } & \multicolumn{4}{|c|}{ Nutritional Status } & \multirow{2}{*}{\multicolumn{2}{|c|}{ Total }} & \multirow{3}{*}{$x^{2}$} & \multirow{3}{*}{$p$} \\
\hline & \multicolumn{2}{|c|}{ Normal } & \multicolumn{2}{|c|}{ Different } & & & & \\
\hline & $\mathrm{n}$ & $\%$ & $\mathrm{n}$ & $\%$ & $\mathrm{n}$ & $\%$ & & \\
\hline \multicolumn{9}{|l|}{ Role } \\
\hline Good & 78 & 88.6 & 10 & 11.4 & 88 & 100 & \multirow{2}{*}{0.369} & \multirow{2}{*}{0.544} \\
\hline Poor & 40 & 83.3 & 8 & 16.7 & 48 & 100 & & \\
\hline \multicolumn{9}{|c|}{ Knowledge } \\
\hline Good & 61 & 88.4 & 8 & 11.6 & 69 & 100 & \multirow{2}{*}{0.102} & \multirow{2}{*}{0.749} \\
\hline Poor & 57 & 85.1 & 10 & 14.9 & 67 & 100 & & \\
\hline
\end{tabular}

In Table 5, results of the statistical test showed that frequencies of mothers in the good knowledge category pertaining to normal nutritional status of children aged 6-36 months were 61 mothers $(88.6 \%)$ and of pertaining to different nutritional status of children aged 6-36 months were 8 mothers (11.6\%), whereas frequencies of mothers in the poor knowledge category pertaining to normal nutritional status of children aged 6-36 months were 57 mothers (85.1\%) and of pertaining to different nutritional status of children aged 6-36 months were 10 mothers $(14.9 \%)$. Frequencies of mothers in the good role category pertaining to normal nutritional status of children aged 6-36 months were 78 mothers $(88.6 \%)$ and of pertaining to different nutritional status of children aged 6-36 months were 10 mothers $(11.4 \%)$, whereas frequencies of mothers in the poor role category pertaining to normal nutritional status of children aged 6-36 months were 40 mothers $(83.3 \%)$ and of pertaining to different nutritional status of children aged 6-36 months were 8 mothers (16.7\%). 
Results of the statistical test showed there were no significant associations between role and knowledge of the mothers and adequate nutritional status of their children aged 6-36 months at a $p$-value of $0.544>0.05$ and $p$-value of $0.749>0.05$ respectively.

\section{Discussion}

\subsection{Mother's Knowledge}

Knoweldge facilitates individuals to gain beneficial information and implement healthy lifestyles. Important factors that influence individuals in gaining of knolwedge are age, level of education and experience.

In view of the Indonesian cultural context some families sometimes give priority to the tertiary needs that abandon the sufficiency of adequate nutritious food, such as jewelry, vehicles, and other similar needs. The importance of adequate nutrition fulfillment is based on three empirical facts. First, sufficient nutritional status is important for health status. Second, sufficient nutrients are necessary for optimal growth to ensure good physical and mental development and long-term health. Third, nutrition science delivers scientific facts that inform the awareness to the public on how to consume and to process foods that contain sufficient nutrients in maintaining health in good condition. Nutritional status of infant and toddler is one of the indicators of community health status and welfare of the public given that infant and toddler are the vulnerable groups to certain disease due to malnutrition.

Results of this study showed that frequencies of the mother's knowledge in children feeding practices in the good category accounted for 69 mothers $(50.7 \%)$ and of mothers pertaining to knowledge of baby feeding in the poor category accounted for 67 mothers $(49.3 \%)$ ). A total of children in the category of good nutritional status were 118 children $(86.8 \%)$ and a total of children in the category of poor nutritional status were 18 children $(13.2 \%)$. Results of the statistical test showed that $p$-value of $0.749>0.05$. Therefore, there was no statistically significant association between mother's knowledge and nutritional status of their children aged 6-36 months.

Frequencies of male children (49.3\%) are almost similar with those of female children (50.7\%). One of the causal factors pertaining to the insignificant association between knowledge of the mothers is gender. This is concide with the study of Bouhlal et al. (2015) that child gender may influence mothers' food choices, as the caloric content of boys' meals was higher than girls'.

Frequencies of the mothers in the category of nurturing care $<2$ child accounted for 94 mothers $(69.1 \%)$ and of the mother in nurturing care $>2$ children accounted for 42 mothers $(30.9 \%)$. On the basis of these figures, it is necessary to have ideal number of children. "Two children is better" is the national slogan released by the State Ministry for Population/National Family Planning Coordinating Board aimed to convey the national message to the Indonesian people for having the ideal number of children for better fulfillment of quantity and quality of household economic and suitable family nutrition (State Ministry for Population/National Family Planning Coordinating Board, 2018). This national slogan is closely related with daily experiences of most mothers in Indonesia that having the ideal number of children facilitates their patience in conducting nurturing care for their children, particularly infant and toddler.

As shown in Table 4, frequencies of the mothers according to their role and knowledge on the nutritional status of their infants and toddlers in the category of good knowledge are 69 mothers $(50.7 \%)$ and of poor knowledge are 67 mothers $(49.3 \%)$ and this means that the difference of knowledge level is $7 \%$. Table 2 shows frequencies of the mothers in the category of housewife and of government employee and private employee are 106 mothers (77.9\%) and 30 mothers $(22 \%)$ respectively with the difference of score between the two categories is $28 \%$. As shown in Table 2 and Table 4, educational background of the mothers is not significantly associated with the nutritional status of their infants and toddlers.

There is a significant association between maternal educational level and healthy eating behaviour in young children and adolescents (Scaglioni et al., 2018). Based on field observations and interviews with respondents, mothers with higher educational level gave greater variation of of food and nutrition for their infants and toddlers and higher knowledge on how to process and to serve food for their children compared to mothers with lower level of education. Most mothers in the category of housewife were so engrossed in their conversations with their neighborhoods in leisure time than spent lower time pertaining to the nutritional status of their infants and toddlers.

Frequencies of the mothers according to their role on the nutritional status of their infants and toddlers in the category of poor level frequencies were 67 mothers (49.3\%) and frequencies of the mothers in the category of housewife are $77.9 \%$ with lower role in terms of economic aspect and frequencies of the mothers in the category of government employee are $4.4 \%$ and of private employee were $17.6 \%$. From field observation, mothers in the category of government employee and of private employee give significant role in terms of economic contribution and higher creativity in giving adequate nutritious food to their infants and toddlers compared to the mothers in the 
category of housewife.

Results of this study pertaining to mother's role and knowledge on the nutritional status of infant and toddler feeding are consistent with those of other studies that found no significant association between maternal nutrition knowledge and stunting, but not wasting in Indonesia (Webb \& Block, 2003; Webb \& Block, 2004). On the contrary, other studies found significant association between mother's feeding knowledge and nutritional status of their children (Siagian \& Halisitijayani, 2014; Sukandar et al., 2015; Hadju et al., 2016; Masthalina \& Agustina, 2017; Ahmad et al., 2018) and the study of Appoh and Krekling (2005) in Ghana found the positive association between mother's nutrition knowledge and underweight, which measures both stunting and wasting. Mothers with above primary level education can significantly reduce stunting and wasting in children.

The inconsistency of results of the studies as mentioned above probably are caused by other determinants including a large size of family members that certainly needs more food proportion or family members. This is also consistent with a study conducted by Fadare et al., (2018) in the Nigerian cultural context that having more children is positively associated with stunting rate in young children. More children, particularly under five children, individual mother commonly tends to increase intra-household competition for childcare resources such that a child is denied adequate nutritional care. This means that delaying age at first birth by a mother is positively associated with better child nutritional outcomes. Therefore, it's desirable that mothers improve their knowledge through health counseling and look for information from mass media regarding adequate processing and serving of adequate nutritious food for their children.

\subsection{Mother's Role}

Overall, results of the study for 136 study subjects showed that there was no significant association between mother's role and the nutritional status of their infants and toddlers in health service area of the Namorambe Community Health Center in Deli Serdang regency. This was proven from chi-square test at $p$-value of $0.544>0.05$. Roles of mothers assessed in this study include mother's care/intention to their young children, breastfeeding for serving supplementary food, psychosocial interactions, hygenic practices and giving health care when their young children had sick. Based on results of cross-tabulation regarding mother's role and the nutritional status of their infants and toddlers, $78(88.6 \%)$ infants and toddlers were classified in the normal status and 10 $(11.4 \%)$ infants and toddlers were classified in the category of different status respectively. On the other hand, 40 mothers $(83.3 \%)$ were classified in the category of good role pertaining to the nutritional status of their infants and toddlersand 8 mothers $(16.7 \%)$ were classified in the category of poor role.

Some respondents were not aware of their practices in giving feeding and restricted the consumption of a particular food that linked to concerns about weight and the child's propensity to gain excess weight. Some mothers identified in this study assume that formula milk can replace breastfeeding for their infants and toddlers although they know that breastfeeding confers numerous benefits for mother and infant. They gave various reasons to limit breastfeeding, i.e. sore nipples or mother's perceptions that she was producing inadequate milk, nipple shape, pain, or damage, birth related pain, employment and length of maternity leave, occupation, education, inadequate breastfeeding knowledge, maternal mobility limitations, positioning difficulties, and frustration at the need for assistance, lack of family and societal support, poor or disorganized suck, and demanding behavior of baby. One of the advantages of infant feeding practices is associated with later childhood dietary habits. Breastfeeding has been proposed as an effective preventive intervention for low intake of vegetables in childhood (Okubo et al., 2015). Besides these factors, respondents are also attracted by new products of formula milk. Therefore, counseling of lactation should be conducted more intensive at community health centers particularly in Deli Serdang regency.

Previous studies have found that factors such as socioeconomic and employment status, maternal and child characteristics, maternal/family intention and health care management contributed to breastfeeding initiation and/or duration (Dennis, 2002; Jones et al., 2011; Meedya et al., 2010; Thulier \& Mercer, 2009). Among those factors, the effect of maternal age on breastfeeding practice is one of the most interesting research targets (OECD, 2012).

\section{Conclusions}

With refers to results of this study, the authors summarize the following conclusion there were no significant associations between role and knowledge of the mothers and adequate nutritional status of their infants and toddlers. 


\section{Suggestions}

\subsection{To Medan Health Polytehnic, Ministry of Health}

1) Consideration pertaining to the implementation of results of this study for public health service.

2) Performing more intensive counseling programs pertaining to adequate nutrition particularly for infants and toddlers.

\subsection{To Community Health Centers}

1) Conducting more intensive nutrition intervention and counseling programs to prevent poor nutritional status of children particularly for infants and toddlers.

2) Improving nutrition counseling programs and suitable health services to reduce nutritional status of infants and toddlers.

\subsection{Mothers}

1) Conducting monitoring of adequate nutritious food to their children and share information concerning on how to serve adequate nutritious food to other mothers.

2) Performing routine check pertaining to weight-for-age (WFA), and weight-for-length (WFL) of their children particularly infants and toddlers at the integrated counseling health posts.

\section{Acknowledgments}

The authors of this study express sincere gratitude to the Institute for Public Service and Policy Research of Medan Health Polytechnic. The authors are grateful also for the revieweers to valuable comments and their constructive comments and suggestions of great benefit to this paper.

\section{Competing Interests Statement}

The authors declare that there are no competing or potential conflicts of interest.

\section{References}

Agras, W. S., Berkowitz, R. I., Hammer, L. C., \& Kraemer, H. C. (1988). Relationships between the eating behaviors of parents and their 18 month old children: A laboratory study. Journal of Eating Disorders, 7 , 461-468. https://doi.org/10.1002/1098-108X(198807)7:4<461::AID-EAT2260070403>3.0.CO;2-Z

Ahmad, A., Madania, S., Dwiriani, C. M., \& Kolopaking, R. (2018). Complementary feeding practices and nutritional status of children 6-23 months old: A Normative study in Aceh Indonesia. Nutr Res Pract, 12(6), 512-520. PMCID: PMC6277313. https://doi.org/10.4162/nrp.2018.12.6.512

Appoh, L. Y., \& Krekling, S. (2005). Maternal nutritional knowledge and child nutritional status in the Volta region of Ghana. Matern Child Nutr., 1(2), 100-10. PMID: 16881885. https://doi.org/10.1111/j.1740-8709.2005.00016.x

Bacon, G. E., Spencer, M. L., Hopwood, N. J., \& Kelch, R. P. (Eds.). (1982). A practical approach to pediatric endocrinology (2nd ed.). Chicago: Year Book Medical Publishers.

Black, R. E., Allen, L. H., Bhutta, Z. A., Caulfield, L. E., De Onis, M., Ezzati, M., ... \& Maternal and Child Undernutrition Study Group. (2008). Maternal and child undernutrition: global and regional exposures and health consequences. The lancet, 371(9608), 243-260. https://doi.org/10.1016/S0140-6736(07)61690-0

Bouhlal, S., McBride, C. M., Ward, D. S., \& Perskya, S. (2015). Drivers of overweight mothers' food choice behaviours depend on child gender. Appetite, 84, 154-160. https://doi.org/10.1016/j.appet.2014.09.024

Dennis C. L., Gagnon, A., Van Hulst, A., Dougherty, G., \& Wahoush, O. (2013). Prediction of duration of breastfeeding among migrant and Canadian-born women: results from a multi-center study. J. Pediatr, 162, 72-79. https://doi.org/10.1016/j.jpeds.2012.06.041

Department of Health of the Republic of Indonesia. (2016). Minister of Health: Nutritional status get improved in Indonesia. Accessed on 27 January 2018.

Dewey, K. G., \& Begum, K. (2011). Long-term consequences of stunting in early life. Maternal and Child Nutrition, 7, 5-18. https://doi.org/10.1111/j.1740-8709.2011.00349.x

Directorate General of Nutrition and Maternal and Child Health. (2015). Decree of Minister of Health, Ministry of Health of the Republic of Indonesia, Jakarta.

Duncan, T. (2001). Commission on Macroeconomics and Health. Health, nutrition and economic prosperity: a 
microeconomic perspective. CMH working paper no WG1:7. Geneva: World Health Organization; 2001.

Eriksson, J. G., Forsen, T., Tuomilehto, J., Osmond, C., \& Barker, D. J. (2001). Early growth and coronary heart disease in later life: longitudinal study. Bmj, 322(7292), 949-953. https://doi.org/10.1136/bmj.322.7292.949

Eriksson, J. G., Forsen, T., Tuomilehto, J., Osmond, C., \& Barker, D. J. (2003). Early adiposity rebound in childhood and risk of Type 2 diabetes in adult life. Diabetologia, 46(2), 190-194. https://doi.org/10.1007/s00125-002-1012-5

Fadare, O., Mavrotas, G., Akerele, D., \& Oyeyemi, M. (2019). Micronutrient-rich food consumption, intra-household food allocation and child stunting in rural Nigeria. Public health nutrition, 22(3), 444-454. https://doi.org/10.1017/S1368980018003075

Food and Agriculture Organization (FAO) of the United Nations. (2014).

Fadare, O., Mavrotas, G., Akerele, D., \& Oyeyemi, M. (2019). Micronutrient-rich food consumption, intra-household food allocation and child stunting in rural Nigeria. Public health nutrition, 22(3), 444-454. https://doi.org/10.1542/peds.2008-3586E

Fadare, O., Mavrotas, G., Akerele, D., \& Oyeyemi, M. (2019). Micronutrient-rich food consumption, intra-household food allocation and child stunting in rural Nigeria. Public health nutrition, 22(3), 444-454. https://doi.org/10.1016/S0140-6736(07)60032-4

Greco, L., Power, C., \& Peckham, C. (1995). Adult outcome of normal children who are short or underweight at age 7 years. Bmj, 310(6981), 696-700. https://doi.org/10.1136/bmj.310.6981.696

Griffiths, L. J., Wolke, D., Page, A. S., \& Horwood, J. P. (2006). Obesity and bullying: different effects for boys and girls. Archives of disease in childhood, 91(2), 121-125. https://doi.org/10.1136/adc.2005.072314

Hadju, V., Yunus, R., Arundhana, A. I., Salmah, A. U., \& Wahyu, A. (2016). Nutiritonal status of infants 0-23 months of age and its relationship with socioeconomic factors in Pangkep. Sicence Alert (2016). https://doi.org/10.3923/ajen.2017.71.76

IFPRI. Global Nutrition Report (GNR). 2014. Actions and Accountability to Accelerate the World's Progress on Nutrition. Washington DC: International Food Policy Research Institute.

Jones, J. R., Kogan, M. D., Singh, G. K., Dee, D. L., \& Grummer-Strawn, L. M. (2011). Factors associated with exclusive breastfeeding in the United States. Pediatrics, 128, 1117-1125. [https://doi.org/10.1542/peds.2011-0841

Levin, H. M., Pollitt, E., Galloway, R., \& McGuire, J. (1993). Micronutrient deficiency disorders. In: Jamison, D. T., Mosley, W. H., Measham, A. R., Bobadilla, J. L. (Eds.), Disease control priorities in developing countries. (2nd ed., pp. 421-451). Oxford (UK): Oxford University Press.

Lim, Z. X., Wong, J. L., Lim, P. Y., \& Soon, L. K. (2018). Knowledge of nutrition during pregnancy and associated actors among antenanatal moters. International Journal of Public Health and Clinical Sciences, 5(1), 2289-7577.

Luiselli, J. K. (1989). Behavioral assessment and treatment of pediatric feeding disorders in developmental disabilities. Progress in Behavior Modification, 24, 91-131.

Masthalina, H., \& Agustina, Z. (2017). Effect of nutrition counseling knowledge and attitude toward mother breasfeeding and baby growth in Lubuk Pakam. Journal of Nutrition and Weigth Loss. https://doi.org/10.21109/kesmas.v12i3.1442

Mathisen, B., Skuse, D., Wolke, D., \& Reilly, S. (1989). Oral-motor dysfunction and failure to thrive among inner-city infants. Develop-mental Medicine and Child Neurology, 31, 293-302. https://doi.org/10.1111/j.1469-8749.1989.tb03998.x

McDonald, C. M., Olofin, I., Flaxman, S., Fawzi, W. W., Spiegelman, D., Caulfield, L. E., ... \& Nutrition Impact Model Study. (2013). The effect of multiple anthropometric deficits on child mortality: meta-analysis of individual data in 10 prospective studies from developing countries. The American journal of clinical nutrition, 97(4), 896-901. https://doi.org/10.3945/ajcn.112.047639

Meedya, S., Fahy, K., \& Kable, A. (2010). Factors that positively influence breastfeeding duration to 6 months: a literature review. Women and birth, 23(4), 135-145. https://doi.org/10.1016/j.wombi.2010.02.002 
Ministry of Health of the Republic of Indonesia. Decree of Health Minister No.1995/Minister of Health/Decree/XII/2010, Ministry of Health of the Republic of Indonesia. Ministry of Health of the Republic of Indonesia, 2017.

Mirsanjari, M., Muda, W. A. M. W., Ahmad, A., Othman, M. S., \& Mosavat, M. (2012). Does nutritional knowledge have relationship with healthy dietary attitude and practices during pregnancy. ICNFS, 39, 159-163.

OECD; Paris. (2012). OECD Family Database. Retrieved July 29, 2015, from http://www.oecd.org/social/family/database.htm

Okubo, H., Miyake, Y., Sasaki, S., Tanaka, K., \& Hirota, Y. (2016). Feeding practices in early life and later intake of fruit and vegetables among Japanese toddlers: the Osaka Maternal and Child Health Study. Public health nutrition, 19(4), 650-657.

Pugliese, M. T., Weyman-Daum, M., Moses, N., \& Lifshitz, F. (1987). Parental health beliefs as a cause of nonorganic failure to thrive. Pediatrics, 80(2), 175-182.

Reilly, J. J., Methven, E., McDowell, Z. C., Hacking, B., Alexander, D., Stewart, L., \& Kelnar, C. J. (2003). Health consequences of obesity. Archives of disease in childhood, 88(9), 748-752. https://doi.org/10.1136/adc.88.9.748

Sachs, J. D., \& McArthur, J. W. (2005). The millennium project: a plan for meeting the millennium development goals. The Lancet, 365(9456), 347-353. https://doi.org/10.1016/S0140-6736(05)17791-5

Sanders, M. R., Patel, R. K, Le Grice, B., \& Sheperd, R. W. (1993). Children with persistent feeding difficulties: An observational analysis of the feeding interactions of problems and non-proble eaters. Health Psychology, 12(1), 64-73. https://doi.org/10.1037//0278-6133.12.1.64

Scaglioni, S., De Cosmi, V., Ciappolino, V., Parazzini, F., Brambilla, P., \& Agostoni, C. (2018). Factors influencing children's eating behaviors: A review. Nutrients. MDPI. https://doi.org/10.3390/nu10060706

Siagian, C. M., \& Halisitijayani, M. (2014). Mother's knowledge on balanced nutrition to nutritional status of children in Puskesmas (Public Health Center in the District of Pancoran Southern Jakarta in 2014 (2015). International Journal of Current Microbilogy and Applied Science, 4(7), 815-826.

State Ministry for Population/National Family Planning Coordinating Board (2018).

Sukandar, D., Khomsan, A., Anwar, F., Riyadi, H., \& Mudjajanto, E. S. (2015). Nutrition knowledge, attitude and practice of mothers and children nutritional status improved after five months nutrition education intervention. International Journal of Basic and Applied Sciences (IJSBAR), 23(2), 424-442.

Thulier, D., \& Mercer, J. Variables associated with breastfeeding duration. J. Obstet. Gynecol. Neonatal. Nurs., 38, 259-268. https://doi.org/10.1111/j.1552-6909.2009.01021.x

UNICEF (2014). Study of Parental Knowledge, Attitudes and Practices Related to Early Childhood Development.

U.S. Centers for Disease Control and Prevention (2016). National Health and Nutrition Examination Survey (NHANES): Anthropometry Procedures Manual. Available at: https://www.cdc.gov/ nchs/data/nhanes/ nhanes-07-08/manual- an.pdf.

Victora, C. G., de Onis, M., Hallal, P. C., Blössner, M., \& Shrimpton, R. (2008). Worldwide timing of growth faltering: revisiting implications for interventions. Pediatrics, 125(3), e473-80. https://doi.org/10.1542/peds.2009-1519

Wardle, J., Guthrie, C. A., Sanderson, S., \& Rapoport. (2001). Development of children's eating behavior questioonaire. Journal of Child Psychology and Psychiatry, 42, 963-870. https://doi.org/10.1111/1469-7610.00792

Webb, P., \& Block, S. (2003). Nutrition knowledge and parental schooling as inputs to child nutrition in the long and short run. Tufts University Friedman School of Nutrition Science and Policy Nutrition Working Paper 3.

Webb, P., \& Block, S. (2004). Nutrition information and formal schooling as inputs to child nutrition. Econ Dev Cult Change, 52(4), 801-20. https://doi.org/10.1086/420901

World Health Organization [WHO]. (2008). Training Course on Child Growth Assessment: WHO Child Growth Standards. Geneva: WHO.

World Health Organization [WHO]. (2014). Comprehensive implementation plan on maternal, infant and young 
child nutrition: An Overview. WHO/NMH/NHD/14.1. ada

World Health Organization [WHO]. (2016). Screening, Assessment and Management of Neonates and Infants with Complications Associated with Zika Virus Exposure in Utero: Rapid Advice Guideline. Accessed on Pebruary 28, 2019.

Yabanci, N., Kisac, I., \& Karakus, S. S. (2013). The effects of mother's nutritional knowledge on attitudes and behaviors of children about nutrition. Journal of Social and Behavioral Sciences, 116(2014), 4477-4481. 5th World Conference on Educational Sciences-WCES 2013, Elsevier. https://doi.org/10.1016/j.sbspro.2014.01.970

Yardımcı, H., Özdoğan, Y., Özçelik, A. Ö., \& Hovland, E. D. (2016). Turkish Adolescents Adherenceto The Mediterranean Diet. The Anthropologist, 25(1,2), 74-179. https://doi.org/10.1080/09720073.2016.11892103

\section{Copyrights}

Copyright for this article is retained by the author(s), with first publication rights granted to the journal.

This is an open-access article distributed under the terms and conditions of the Creative Commons Attribution license (http://creativecommons.org/licenses/by/4.0/). 